\title{
PEMODELAN DAN ANALISIS WIRELESS MESH NETWORK DENGAN ARSITEKTUR PUBLISH-SUBSCRIBE DAN PROTOKOL MQTT
}

\author{
Kasyful Amron ${ }^{1}$, Eko Sakti P. ${ }^{2}$, Mahendra Data ${ }^{3}$ \\ 1,2,3 Fakultas Ilmu Komputer Universitas Brawijaya Malang \\ Email: [kasyful, ekosakti, mahendra.data]@ub.ac.id
}

(Naskah masuk: 20 Mei 2016, diterima untuk diterbitkan: 20 Juni 2016)

\begin{abstract}
Abstrak
Akses terhadap informasi menjadi kebutuhan yang sangat penting bagi manusia. Namun, tidak semua daerah memiliki akses yang layak terhadap informasi terutama daerah terpencil dikarenakan keterbatasan infrastruktur komunikasi. Teknologi wireless mesh network (WMN) dapat menjadi salah satu solusi untuk mengatasi masalah keterbatasan infrastruktur tersebut. Untuk meningkatkan performa WMN, maka perlu adanya rancangan mekanisme pengiriman informasi yang efisien. Ide penelitian ini pada dasarnya adalah memberikan solusi pengiriman informasi menggunakan arsitektur publish subscribe. Protokol publish subscribe yang digunakan adalah protokol MQTT (Message Queuing Telemetry Transport). Pada penelitian ini dilakukan pengujian terhadap Quality of Service seperti throughput, delay, jitter, dan packet loss untuk keseluruhan node. Pada pengujian QoS arsitektur WMN maupun MTQQ menunjukan bahwa kualitas layanan dipengaruhi oleh jarak,jumlah node yang dilewati dan material yang menghalangi. Seperti yang ditunjukan pada hasil pengujian antara node yang dihalangi tiga tembok beton, packet lossnya mencapai $88.8 \%$ dan delaynya sebesar $2.493,79 \mathrm{~ms}$.
\end{abstract}

Kata kunci: wireless, mesh network, publish and subscribe

\begin{abstract}
Has an access to the information becomes a very important requirement for humans. However, not all areas are have adequate access to information, especially in rural areas due to limited communication infrastructures. Wireless mesh network (WMN) technology may be can act as one alternative solution to overcome the problems. To improve the performance of WMN, it is necessary to design efficient information delivery mechanism. The idea of this research is basically giving information delivery solutions using the publish subscribe architecture. Publish-subscribe protocol used here is the MQTT protocol (Message Queuing Telemetry Transport). In this research, the Quality of Service testing such as throughput, delay, jitter, and packet loss for the entire node. On testing and MTQQ WMN QoS architecture shows that quality of service is affected by distance, number of nodes that pass and blocking material. As shown in the test results between nodes that hindered three concrete walls, packet lossnya reached $88.8 \%$ and the delay amounted to $2493.79 \mathrm{~ms}$.
\end{abstract}

Keywords: wireless, mesh network, publish and subscribe

\section{PENDAHULUAN}

Dewasa ini, akses terhadap informasi menjadi kebutuhan yang sangat penting bagi manusia. Dengan adanya akses informasi tersebut, manusia dapat saling berinteraksi, bertukar ide dan menambah pengetahuan yang pada gilirannya dapat meningkatkan daya saing bangsa. Sayangnya, tidak semua daerah di Indonesia memiliki akses yang layak terhadap informasi, terutama di daerah terpencil. Sebagai gambaran, pengguna internet di Indonesia masih didominasi oleh warga perkotaan dengan persentase sekitar 83,4 persen (Donny, 2014).

Permasalahan tersebut di atas terutama disebabkan oleh kurang meratanya pembangunan infrastruktur telekomunikasi di Indonesia. Kondisi geografis Indonesia yang berbentuk kepulauan dengan banyak gunung menyulitkan instalasi infrastruktur telekomunikasi baik yang menggunakan media kabel maupun nirkabel dengan base station berukuran besar. Beberapa program sudah dilaksanakan pemerintah untuk meningkatkan pemerataan penetrasi internet antara lain adalah Pusat Layanan Internet Kecamatan (PLIK) dan Mobile PLIK. Hanya saja, layanan tersebut masih kesulitan mengakses daerah terpencil dikarenakan keterbatasan sumber listrik dan kondisi lokal yang sulit. Oleh karena itu, tetap diperlukan instalasi infrastruktur jaringan telekomunikasi pada daerah terpencil yang dengan biaya murah sekaligus sesuai dengan kondisi geografis daerah tersebut.

Alternatif teknologi yang dapat diterapkan adalah wireless mesh network (WMN) yaitu sebuah jaringan komunikasi yang terdiri dari perangkatperangkat radio yang disusun dengan menggunakan topologi mesh. Pada WMN, setiap perangkat dapat berkomunikasi dengan perangkat lainnya dalam satu jangkauan komunikasi secara langsung melalui mode ad-hoc (Axyldiz, 2005). Jejaring perangkat nirkabel 
tersebut dapat dimanfaatkan sebagai perantara untuk meneruskan data yang dikirim dari satu ujung ke ujung lainnya.

Performa WMN sendiri banyak dipengaruhi oleh desain topologi, konfigurasi perangkat keras dan perangkat lunak serta arsitektur komunikasi yang dipakai. Topologi, konfigurasi perangkat keras dan perangkat lunak berpengaruh ke aspek fisik pembentukan jaringan, sedangkan arsitektur komunikasi berpengaruh terhadap efisiensi penyediaan informasi untuk pengguna yang meliputi aspek pengiriman dan penyimpanan data (Axyldiz, 2005).

Publish/subscribe (pub-sub) merupakan salah satu arsitektur komunikasi dimana informasi yang dikirimkan oleh pengirim atau publisher diklasifikasikan menjadi beberapa kelas untuk kemudian disimpan oleh perantara atau broker (Liu, 2003). Penerima informasi atau subscriber hanya menerima informasi dari broker sesuai dengan kelas yang diminatinya. Dengan kata lain, publisher tidak perlu tahu siapa subscriber dari informasi yang dikirimnya. Lebih jauh lagi, publisher dan subscriber tidak perlu ada pada waktu yang bersamaan saat pengiriman pesan berlangsung. Dengan konsep seperti ini, informasi dapat dikirimkan secara efisien karena subscriber hanya menerima pesan sesuai dengan kelas yang diminatinya. Selain itu, jika jalur komunikasi subscriber terputus untuk sementara waktu, dia tetap dapat memperoleh informasi dari publisher segera setelah jalur komunikasinya tersambung kembali. Salah satu protokol yang menerapkan arsitektur publish subscribe adalah protokol MQTT (Message Queuing Telemetry Transport). MQTT dipilih karena dalam operasinya dia hanya membutuhkan pertukaran data dalam ukuran relatif kecil. Selain itu, MQTT mempunyai tiga level Quality of Service (QoS) yang menetukan tingkatan kepastian sampai ke subscriber. Ide penelitian ini pada dasarnya adalah memodelkan dan menganalisa pengiriman informasi menggunakan arsitektur publish subscribe pada WMN yang suatu saat dapat diterapkan untuk berbagai kondisi daerah di Indonesia terutama pada daerah terpencil.

\section{TINJAUAN PUSTAKA}

Wireless Mesh Network (WMN) merupakan sebuah jaringan komunikasi yang terdiri dari perangkat-perangkat radio yang disusun dengan menggunakan topologi mesh seperti ditunjukan pada Gambar 2.1. Pada WMN, setiap perangkat secara otomatis membentuk jaringan ad-hoc dimana mereka dapat saling berkomunikasi langsung tanpa mengharuskan salah satu menjadi pusat komunikasi atau access point (Axyldiz, 2005). Terdapat dua jenis perangkat pada WMN: mesh router dan mesh client. Kumpulan mesh router membentuk sebuah jejaring perangkat yang dapat dimanfaatkan sebagai perantara untuk meneruskan data yang dikirim dari satu ujung ke ujung lainnya. Untuk menunjang fungsionalitas tersebut, beberapa protokol routing telah diusulkan antara lain :multi-radio routing, multi-path routing, hierarchical routing dan geographic routing (Draves, 2004) (Frey, 2004). Selain itu, mesh router juga mempunyai kemampuan sebagai gateway yaitu jalan keluar masuknya data dari mesh client ke jejaring mesh router dan sebaliknya.

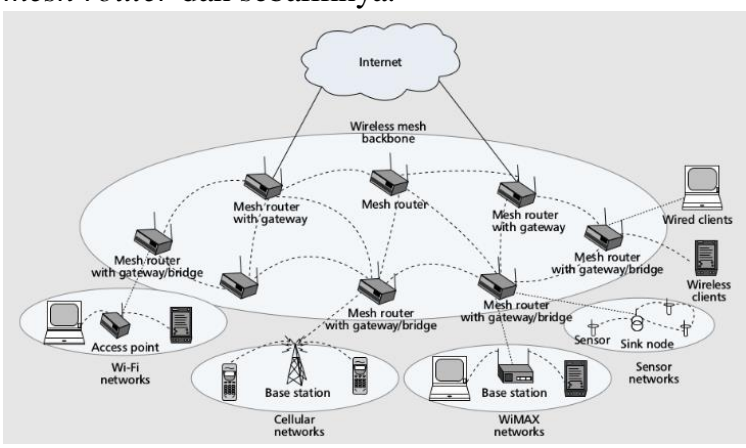

Gambar 2.1 Topologi umum WMN

Salah satu tantangan pada jaringan WMN adalah bagaimana merancang dan menerapkan metode pengiriman data antar pengguna secara efisien pada daerah terpencil dengan infrastruktur komunikasi yang terbatas dan tidak selalu tersedia.

Dengan kata lain, dibutuhkan suatu mekanisme yang memungkinkan pengirim dan penerima pesan tidak perlu ada pada waktu yang bersamaan saat pengiriman pesan berlangsung (time decoupling). Arsitektur komunikasi yang dapat memenuhi kriteria di atas adalah arsitektur komunikasi pubish subscribe (pub-sub).

Pada pub-sub, informasi yang dikirimkan oleh pengirim atau publisher diklasifikasikan menjadi beberapa kelas untuk kemudian disimpan oleh perantara atau broker (Liu, 2003). Penerima informasi atau subscriber hanya menerima informasi dari broker sesuai dengan kelas yang diminatinya. Dengan kata lain, publisher tidak perlu tahu siapa subscriber dari informasi yang dikirimnya.

Lebih jauh lagi, publisher dan subscriber tidak perlu ada pada waktu yang bersamaan saat pengiriman pesan berlangsung.Dengan konsep seperti ini, informasi dapat dikirimkan secara efisien karena subscriber hanya menerima pesan sesuai dengan kelas yang diminatinya.Selain itu, jika jalur komunikasi subscriber terputus untuk sementara waktu, dia tetap dapat memperoleh informasi dari publisher segera setelah jalur komunikasinya tersambung kembali.

Untuk mengimplementasikan arsitektur pubsub, salah satu protokol yang dapat digunakan adalah protokol MQTT (Message Queuing Telemetry Transport) (Lampkin, 2012) (Wagle, 2016). MQTT memiliki beberapa karakteristik :

1. Publish/subscribe yaitu protokol bekerja dengan prinsip pengirim (publisher) mempublikasikan informasi dan penerima (subscriber) berlangganan informasi sesuai topik yang diminati. Pengiriman pesan diperantarai oleh broker. 
2. Topics and subscription yaitu penerima pesan (subscriber) hanya menerima informasi yang berkaitan dengan topik yang diminatinya.

3. Quality of Service (QoS) leveling yaitu terdapat beberapa tingkatan kepastian pesan sampai ke subscriber. Hal ini penting mengingat publisher dan subscriber tidak harus ada pada waktu yang bersamaan.

4. Retained message yaitu informasi yang dikirim subscriber disimpan oleh broker. Jika ada subscriber baru pada topik tersebut, maka informasi yang disimpan akan dikirimkan ke subscriber baru tersebut.

Quality of service dari arsitektur MQTT dapat diukur dengan menggunakan beberapa parameter seperti throughput, jitter dan packet loss. Throughput merupakan jumlah rate paket yang sukses terkirim melalui suatu kanal komunikasi pada satuan waktu tertentu (persecond). Sehingga semakin tinggi throughput menunjukkan sistem atau arsitektur tersebut handal ketika harus menangani load dalam jumlah besar. Jitter dalam jaringan computer merupakan variasi delay yang terjadi pada jaringan computer yang bisa disebabkan oleh congestion pada link. Variasi delay dapat menunjukkan kestabilan sistem tersebut. Semakin besar variasi delay pada suatu link menunjukan link tidak stabil dalam menangani load. Dalam komunikasi wireless ketidak stabilan tersebut bisa dipengaruhi beberapa faktor seperti congestion, interferensi, maupun hambatan yang disebabkan oleh material yang dilewati gelombang elektromagnetik. Sedangkan parameter packet loss menunjukan persentasi data yang loss akibat dampak dari congestion, interferensi, maupun hambatan.

\section{PERANCANGAN SISTEM}

\subsection{Arsitektur sistem}

Ide penelitian ini diawali dengan kegiatan membuat model atau prototipe dari perangkat yang akan menjadi wireless mesh router. Prototipe perangkat tersebut dibangun dari komputer mini yang banyak beredar di pasaran yaitu Raspberri Pi seperti ditunjukkan pada Gambar 3.1. Raspberry Pi dipilih karena berharga relatif murah, berukuran kecil, mempunyai kemampuan komputasi yang mencukupi dengan tingkat konsumsi daya relatif rendah sehingga cocok dipakai pada daerah terpencil dengan sumber daya listrik terbatas. Prototipe tersebut juga dibekali dengan modul komunikasi wireless dengan protokol IEEE $802.11 \mathrm{~b} / \mathrm{g} / \mathrm{n}$ yang akan beroperasi dalam mode ad-hoc.

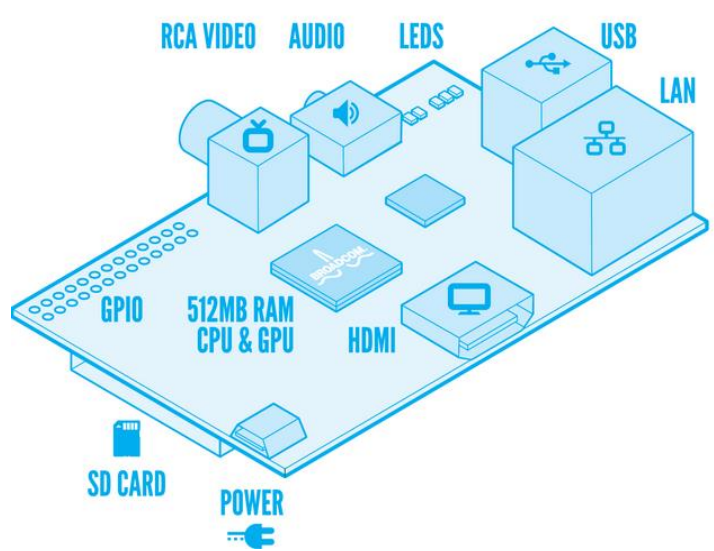

Gambar 3.1 Arsitektur Raspberry Pi

Perangkat-perangkat mesh router tersebut akan dipasang sehingga membentuk jejaring perangkat dengan topologi mesh seperti ditunjukkan pada perangkat berkode MR pada Gambar 3.2. Agar dapat berfungsi sebagai perantara yang meneruskan data dari lokasi A ke lokasi B, prototipe tersebut dibekali dengan implementasi protokol routing pada WMN. Terdapat beberapa alternatif protokol routing yang dapat diimplementasikan antara lain : $A O D V$, OLSR, Batman, dan Babel. Selanjutnya, beberapa mesh router tersebut akan diatur sebagai gateway sebagai jalan keluar masuknya data dari pengguna ke jaringan WMN dan sebaliknya.

Agar dapat berkomunikasi dengan perangkat komunikasi milik pengguna, gateway tersebut akan disambungkan ke sebuah perangkat wi-fi router yang berfungsi sebagai access point $(A P)$.

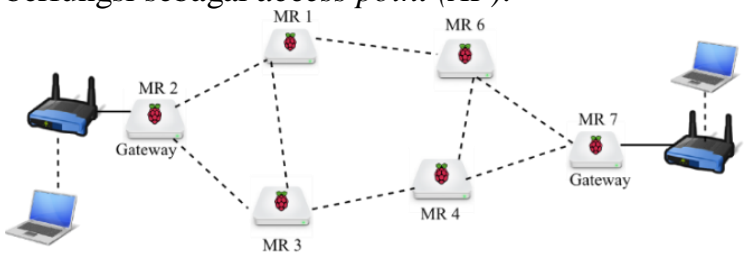

Gambar 3.2 Rancangan topologi pada penelitian

Selanjutnya, untuk mengimplementasikan arsitektur komunikasi publish subscribe dengan protokol MQTT, pada tiap gateway tersebut akan dipasang aplikasi Mosquitto yang berfungsi sebagai broker data. Pada ide penelitian ini juga akan dibangun dua buah aplikasi masing-masing untuk publisher dan subscriber yang mempunyai kemampuan untuk bertukar pesan dan berkas dengan metode publish subscribe. Aplikasi tersebut dibangun dengan memanfaatkan fungsi pemrograman yang disediakan oleh Eclipse Paho..

Mesh Router (MR) pada sistem ini dibangun dengan menambahkan perangkat $802.11(\mathrm{~b} / \mathrm{g} / \mathrm{n})$ pada raspberry seperti pada Gambar 3.3. 


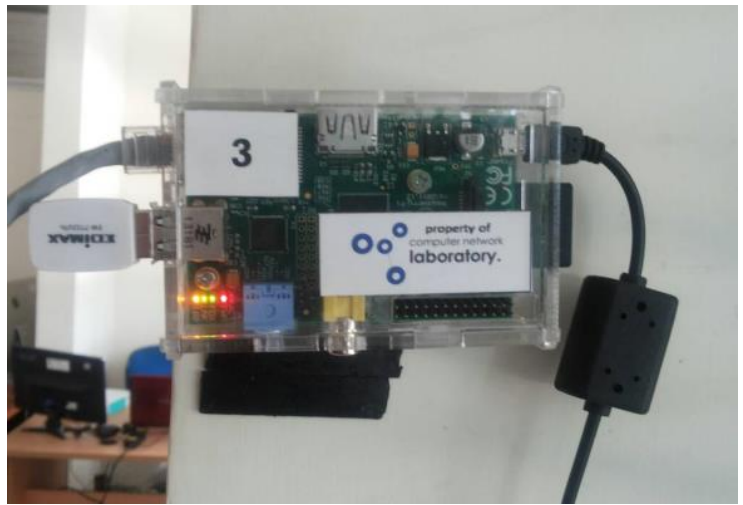

Gambar 3.3 Raspberry Pi Seri B dengan Modul WiFi Edimax

Pada penelitian ini, router-router yang sudah dirancang kemudian disusun membentuk sebuah jaringan dengan topologi jenis mesh seperti diilustrasikan pada Gambar 3.2. Router dirancang untuk bekerja pada mode Ad-Hoc yang memungkinkan sebuah node wifi dapat berkomunikasi dengan node wifi lain tanpa menggunakan perangkat Access Point sebagai perantara. Agar dapat saling meneruskan data, pada setiap router dipasang protokol routing OLSR (Optimized Link State Routing).

\section{PENGUJIAN}

Pengujian yang dilakukan menggunakan 6 node dan dihubungkan secara wireless di tiap-tiap node dengan menggunakan mesh. Terdapat dua skenario pengujian yang dilakukan yaitu :

\section{Pengujian Quality of Service (QoS) Jaringan WMN}

Pengujian ini bertujuan untuk mengukur kualitas jaringan WMN yang dibangun. Terdapat 3 parameter pengukuran yang diuji yaitu throughput, jitter, dan packet loss. Pengujian dilakukan dengan mengirimkan data dengan ukuran bervariasi antara lain $13 \mathrm{MB}, 16 \mathrm{MB}$, dan 19 MB dari satu node pusat yang sudah ditentukan ke node-node yang lain.

\section{Pengujian Unjuk Kerja Protokol MQTT} pada Jaringan WMN

Pengujian ini bertujuan untuk mengukur unjuk kerja protokol MQTT pada jaringan WMN. Untuk melakukan pengujian ini, pada node 2 dipasang perangkat lunak Mosquitto yang berperan sebagai broker untuk meneruskan data dari publisher ke subscriber. Selain dipasangi broker, node 2 juga berperan sebagai subscriber. Subscriber tersebut akan menerima data yang dikirimkan oleh publisher yang diperankan oleh node lain. Selanjutnya, pada pengujian ini diukur rata-rata delay waktu yang dibutuhkan dari pesan dikirim oleh oleh publisher sampai diterima oleh subscriber.

\subsection{Topologi}

Pengujian ini dilakukan di Gedung C, Fakultas Ilmu Komputer, Universitas Brawijaya. Topologi jaringan yang dipakai dalam pengujian diilustrasikan pada Gambar 4.1

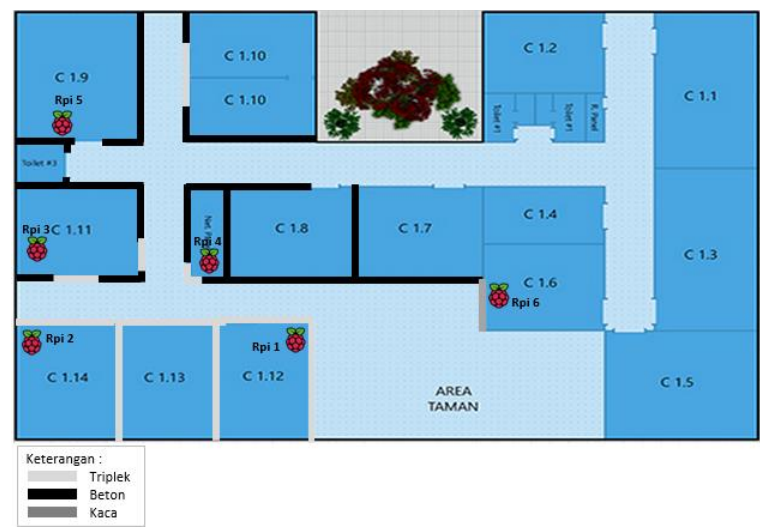

Gambar 4.1 Topologi jaringan dalam pengujian

\subsection{Hasil Skenario 1}

Dari hasil pengujian ditunjukkan bahwa penggunaan arsitektur mesh dipengaruhi faktorfaktor seperti jarak antar node, media atau hambatan yang dilewati seperti tembok beton, triplek, kaca. Faktor-faktor tersebut menyebabkan perbedaan performansi pada tiap-tiap skenario pengujian seperti yang ditunjukan pada Gambar 4.2 , 4.3 dan 4.4.

Hasil pengujian sesuai skenario 1 diperoleh data yang dapat mendukung dari konsep umum pada tiap parameternya. Pada umumnya throughput akan naik ketika paket yang dikirimkan semakin besar, hal ini dapat dilihat dari tiap skenario uji di atas yang memiliki kecenderungan naik. Latency disebabkan karena hambatan dan jarak antar node. Latency ini merupakan waktu tempuh antara koneksi dari node satu ke node yang lainnya dan ketika menemukan hambatan dan jarak yang jauh tersebut waktu tempuhnya akan cenderung lama. Packet loss akan semakin meningkat pula ketika melewati hambatan tembok beton dan didukung oleh jarak yang semakin jauh. Gambar 4.2 , 4.3 dan 4.4 berikut merupakan ringkasan hasil pengujian..

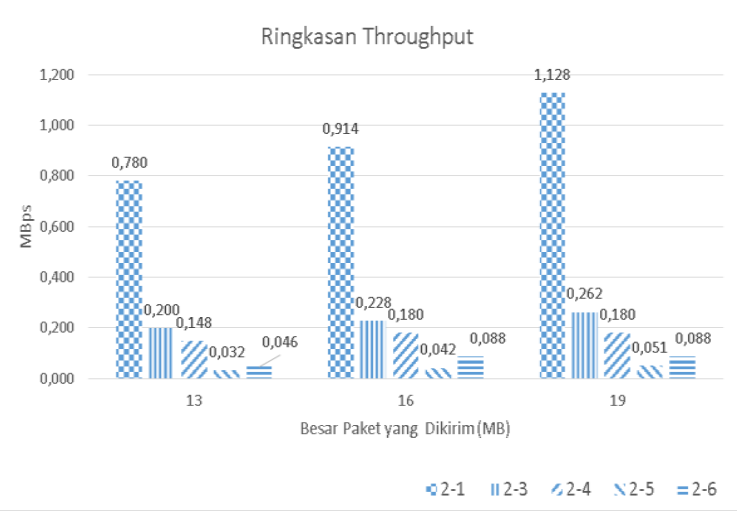

Gambar 4.2 Throughput Hasil Pengujian 


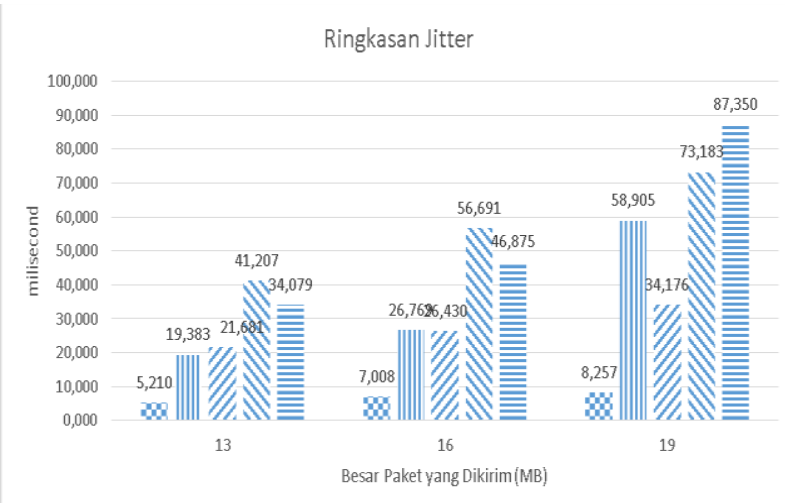

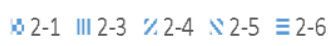

Gambar 4.3 Jitter Hasil Pengujian

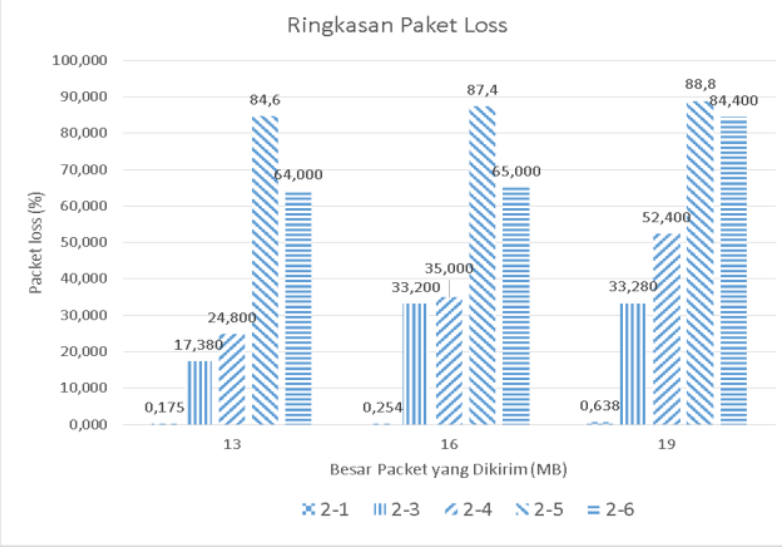

Gambar 4.4 Packet Loss Hasil Pengujian

Hasil pengujian Gambar 4.3, 4.3 dam 4.4 menunjukkan bahwa koneksi dari node 2 ke node 1 relatif lebih baik meskipun saat pengiriman paket sebesar 19MB mengalami kenaikan jumlah paket loss. Namun packet loss pada pengiriman tersebut masih dibawah $1 \%$. Hal ini dikarenakan selain jarak yang dekat antara node tersebut, juga dikarenakan material yang menghalangi berupa triplek (lembaran kayu). Sedangkan pada komunikasi antara node 2 ke 5 menunjukkan bahwa hampir seluruh paket yang dikirim loss $(88,8 \%$ packet loss $)$. Hal ini disebabkan banyaknya halangan yaitu 1 tembok triplek dan 3 lapis tembok beton serta jarak yang cukup jauh antara node tersebut.

\subsection{Hasil Skenario 2}

Tabel 4.1 Delay MQTT

\begin{tabular}{|l|l|}
\hline Node & Delay $(\mathrm{ms})$ \\
\hline 1 & 24,94 \\
\hline 3 & 69,95 \\
\hline 4 & 213,57 \\
\hline 5 & $2.493,79$ \\
\hline 6 & 50,42 \\
\hline
\end{tabular}

Pada pengujian MQTT juga ditunjukkan bahwa delay yang tertinggi yaitu pada node 5 yang dikarenakan jarak dan rintangan yang menghalangi gelombang elektromagnet. Hal ini bisa menadi faktor yang menyebabkan banyaknya packet loss yang terjadi pada saat pengiriman ke node 5 .

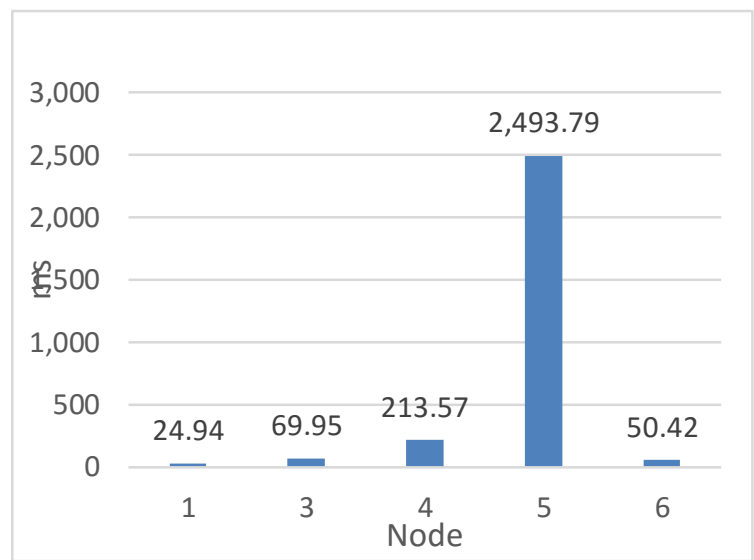

Gambar 4.5 Grafik Delay MQTT

\section{KESIMPULAN}

Dari hasil penelitian yang sudah dilakukan sejauh ini didapatkan beberapa hal berikut :

1. Router WMN dapat dibangun dengan menggunakan mikrokomputer Raspberry Pi sebagai perangkat komputasi dan transceiver wifi sebagai perangkat komunikasi.

2. Agar dapat meneruskan data, setiap router pada jaringan WMN harus bekerja pada mode Ad hoc dan menjalankan protocol routing OLSR.

3. Performa WMN dapat diukur dengan parameter QOS meliputi : delay, packet loss dan throughput.

4. Performa WMN dan MQTT dipengaruhi oleh banyaknya hop atau jumlah router yang harus dilewati untuk mengirimkan sebuah data, jenis halangan antar router dan besar data yang dikirimkan.

5. Penyebab utama kegagalan pengiriman data adalah faktor lingkungan berupa penghalang yang terbuat dari tembok beton. Penghalang ini dapt menyebabkan packet loss hingga $88.8 \%$.

\section{SARAN}

Saran yang dapat disampaikan untuk pengembangan lebih lanjut adalah perlu dilakukan pengujian dengan scenario waktu pengujian yang berbeda untuk mengetahui pengaruh kondisi lingkungan pada waktu yang berbeda terhadap performa WMN.

\section{DAFTAR PUSTAKA}

AXYILDIZ, I. F., WANG, XUDONG. 2005. A Survey on Wireless Mesh Networks. IEEE 
Communication Magazines, Vol. 43 Issue 09.

BELDING, E. M., et al. 2003. Multi-Level Hirarchies for Scalable Ad-Hoc Routing. ACM/Kluwer Wireless Networks (WINET), Vol.9 No. 5, pp.461-478.

DONNY, B. U. et al. 2014. Catatan Ringkas Tata Kelola dan Praktik Internet Indonesia. ICT Watch Indonesia.

DRAVES, R., PADHYE, J., ZILL, B. 2004. Routing in Multi-Radio, Multi-Hop Wireless Mesh Networks. ACM Annual International Conference on Mobile Computing and Network (MOBICOM), pp. 114-128.

FREY, H. 2004. Scalable Geographic Routing Algorithms for Wireless Ad-Hoc Networks. IEEE Network Magazines, pp.18-22.

LAMPKIN, V., et al. 2012. Building Smarter Planet Solutions with MQTT and IBM WebSphere MQ Telemetry.

LIU, Y., PLALE, B. 2003. Survey of Publish Subscribe Event Systems. Computer Science Dept., Indiana University.

WAGLE, S., 2016. Semantic Data Extraction over MQTT for IoT Centric Wireless Sensor Networks. 2016 International Conference on Internet of Things and Applications (IOTA). IEEE, hal. 227-232. Tersedia di: http://ieeexplore.ieee.org/abstract/document /7562727/. 